\title{
Chapter 7 \\ Time Regulation as Institutional Condition for Children's Outdoor Play and Cultural Formation in Kindergarten
}

\author{
Åsta Birkeland and Hanne Værum Sørensen (1)
}

\begin{abstract}
Time regulation is an important aspect of the everyday life in any kindergarten and has an impact on which activities are given priority. In this case study, the outdoor playtime in one kindergarten in China and one in Norway is compared based on the understanding that children's cultural formation develops in a dialectical relationship between children's interests and motives and societal, institutional, and weather conditions. The aim of the article is to identify how time regulations provide conditions for children's play and cultural formation during outdoor playtime. The research question is: How does institutional time regulation interplay with the pedagogical practice and children's activities in the outdoor playtime? Employing a cultural-historical approach, drawing on Hedegaard's concepts of development and cultural formation as an individual, institutional and societal process, the dialectical interplay between institutional time regulation and children's engagement in outdoor activities is the unit of analysis in this study. Our findings indicate that the kindergarten teachers in the Chinese kindergarten as well as the Norwegian kindergarten aim to adjust the pedagogical content and time schedule to the traditions, values, and conditions in both countries. This chapter contributes to knowledge about the interplay between institutional conditions and children's activities and cultural formation in outdoor play.
\end{abstract}

Keywords Kindergarten - Outdoor play · Time regulation - Cultural formation · China - Norway

The original version of this chapter was revised: Acknowledgement has been included at the end of the chapter. The correction to this chapter is available at https://doi.org/10.1007/978-3-03072595-2_12

\footnotetext{
A. Birkeland $(\bowtie)$

Western Norway University of Applied Sciences, Bergen, Norway

e-mail: Asta.Birkeland@hvl.no

H. V. Sørensen

VIA University College, Aarhus, Denmark

e-mail: hsor@via.dk
} 


\subsection{Introduction}

Outdoor play in kindergarten is a crucial part of everyday life in kindergartens globally, and is organized as a temporally and culturally re-occurring event in most kindergartens ${ }^{1}$ (Bang, 2009; Birkeland, 2019). The importance of outdoor activities in kindergartens has received increased concern and focus globally (Waller, Ærleman-Hagser, \& Sandseter, 2017).

Concern for children's health and general well-being due to limited physical activity have been major topics in prior research (Dowda, Pate, Trost, Almeida, \& Sirard, 2004; Dowda et al., 2011; Karlsson, 2012). Studies of outdoor play have made inquiries into the quality of the design and equipment in outdoor playgrounds by using the ECERS rating scale (Dowda et al., 2004, 2011; Hu, Marco, \& Chen, 2015; Sørensen, 2013). Other studies have focused on the different purposes of outdoor playtime such as risky play (Sandseter and Lysklett, 2017), exploration of nature (Hammer \& He, 2016), physical education and health effects (Brussoni, Gibbons, \& Gray, 2015; Liu \& Tobin, 2018), and play in general (Sørensen, 2013; Sørensen \& Birkeland, 2020).

However, the conditions for outdoor play vary according to societal expectations and demands, institutional practices, personal motivation by children and teachers (Hedegaard, 2009), and weather conditions (Sørensen \& Birkeland, 2020). This article is based upon an understanding that children's outdoor play develops in a dialectical relation between these conditions.

Time regulation as such is not a neutral practice, but rather is value-laden, indicating what focus is prioritized. How everyday life in kindergarten is structured is an indication of the intentions and goals which have become more or less tacit (Birkeland, 2019). The everyday structure and program have been neglected as a focus for research on outdoor play, despite it being an important institutional condition for children's outdoor play. This chapter investigates time regulations of children's activities in the outdoor playtime in one kindergarten in China and one in Norway, thus obtaining insight into local practices (Flyvbjerg, 2011; Stake, 2005; Yin, 2009) of outdoor play activities and nuancing the understandings of how the outdoor playtime in kindergarten are conditioned of institutional, societal and cultural differences. The aim of the chapter is to identify how time regulations of the outdoor activities intersect with children's engagement in outdoor play activities, and thereby provide varied conditions for children's play and cultural formation in different institutions. The primary research question is therefore: How does institutional time regulation interact with pedagogical practice and children's activities in outdoor playtime?

\footnotetext{
${ }^{1}$ Kindergarten in some English-speaking countries, including the United States, refers to the first year of elementary school. In this article kindergarten refers to programs in China and Norway that are independent from the elementary school systems. In China, kindergartens (you'eryuan) primarily provide early childhood education and care to children from 3 to 6 years old. In Norway, kindergarten (barnehage) refers to institutions for children 1 to 6 years old. Throughout the article, we use the term kindergarten to refer to similar programs in China and in Norway.
} 
Studying varieties of interplay between institutional conditions such as time regulation and children's engagement in play will contribute to understanding the complexity of institutional practices and outdoor play activities. We have chosen two kindergartens situated in different cultural contexts with different societal and institutional expectations and demands and different climate and weather conditions to illustrate varieties of interplay between time regulation and children's activities. Furthermore, we will analyse video observations of children's and kindergarten teachers' transitions from indoor to outdoor activities and compare how institutional time regulation in two different kindergartens interact with children's engagement in outdoor activities and play.

The dominant outdoor practices in Chinese kindergartens have favoured Guangbo ticao, morning group exercises (Liu \& Tobin, 2018) and physical education lessons such as structured physical activities in which children mimic demonstrated gross motor movements, over outdoor free play (Hu et al., 2015). Hu et al. emphasize that the design of outdoor play space lacks diversity in the design of play areas. There is a growing concern in China for how rapid urbanization is depriving children of natural play areas. Researchers have also paid increased attention to this development (Wang, Woolley, Tang, Liu, \& Luo, 2018). The main concern for early childhood education (ECE) in China today is to give more time and space for child-initiated play and unstructured activities in the outdoor playground (Wang et al., 2018).

The dominant practice in Norwegian kindergartens has been to give extensive time for outdoor activities and to let children have access to natural environment and outdoor play spaces (Moser \& Martinsen, 2010). Kallestad and Ødegaard (2013) illuminate that the activities in Norwegian kindergartens typically result from children's own initiatives, so also in the outdoor playtime. They explain this through the concept of "free play" as child-initiated play, which is well embedded in Norwegian kindergartens' culture and tradition. However, the dialectic between time regulation, institutional practices, and children's outdoor play have been given less priority (Birkeland, 2019).

In the following sections, we will elaborate on the theoretical perspectives of our study, and subsequently will describe the methodological and analyses approaches. In the results section, we will present the general time schedule in the two kindergartens, the time schedule for outdoor playtime, and the time regulation of transitions between activities. The discussion section will consider how time regulation provides conditions for play and cultural formation. Finally, we present the implications of our study.

\subsection{Theoretical Framework}

The theoretical framework of this study is based upon a cultural-historical research tradition, understanding children's learning, development, and cultural formation as a dialogical process between the child and the environment (Vygotsky 1966, 1998). Leontiev (2005) argues that child development must be understood as more 
complex than an unfolding of the child's abilities and talents, and that it is not sufficient to view the environment as a single factor contributing to the unfolding of the child's attributes. We need to understand children's development from a wholeness perspective; that is, as a dynamic and dialectical process between the person's activities, intentions and motives, institutional traditions and practices, societal demands, and material conditions (Hedegaard, 2009, 2012). From this perspective, children are viewed as active agents interacting with their surroundings (Hedegaard, 2012; Leontiev, 2005; Vygotsky, 1998).

Conditions for social situations are shaped at different levels (Hedegaard, 2008a, 2014) including the societal, institutional, and personal levels, and the dialectical relations between these levels. An additional dimension was added in Sørensen and Birkeland's study (2020), which highlighted how climate, weather, and air quality also provide conditions for pedagogical practice.

The societal perspective in Hedegaard's (2012) model elaborates on the historically developed context of the society, in which traditions and values are developed through generations and implemented in laws and policy documents. In Hedegaard's model of children's activity settings in various institutions (2012), the societal perspective is depicted as cultural traditions in the multiple institutions of society, which in this study refer to the different cultural historical value positions in China and Norway.

Societal conditions for early childhood institutional practice include location and housing, the kindergarten's physical and economic conditions, and structures and routines of the day based on the societal demands, as interpreted by the kindergarten teachers and managers in cooperation with parents. These conditions influence the social practices and activity settings in which the children may take part. Societal conditions and political decisions also influence the education of the professionals responsible for pedagogical practice at the institutional level of kindergartens.

Institutional practices in kindergarten create conditions for the activity settings and children's learning and development. These everyday practices should be viewed as working towards connecting and fulfilling societal traditions, values, and anticipations with personal motives, education, values, and ideas for the benefit of children. Cultural ideas form in the interactions of everyday practices, but they also refer to values and meanings far beyond the institutional sphere (Gulløv \& Højlund, 2003, p. 142).

The personal perspective includes adults and children as participants in different institutional settings. The teachers in kindergarten and school are part of society, socialised through their own upbringing and education and their understanding of the demands and expectations put on them by society, the local municipality, and parents. The children have their first social experiences in the family, where they are socialised into traditions and norms in their own family, before they meet and interpret the demands and expectations of kindergarten teachers and other children. Since children in China usually enter kindergarten at the age of three and as many as $84.4 \%$ of children in Norway attend kindergarten from the age of one (Statistic in Norway, 2019) children are exposed to a double-socialisation process (Sommer, 2003). 
Activity settings are planned and organized situations or shared activities in the pedagogical practice in kindergarten, in which children are expected to participate (Hedegaard, 2012), such as outdoor playtime. Analysing and conceptualising what is occurring in an activity setting means investigating the societal and institutional conditions for the activity setting together with the demands on children and kindergarten teachers in the social situation.

In most cases, the original time regulation is based on intentional and conscious choices of action to reach specific goals. Time regulation is thereby not a neutral dimension of the everyday life of kindergarten, but rather reflects societal demands as well as institutional practices. This implies that, for example, the time schedule can be traced back to what former kindergarten teachers have tried to achieve and what the object of kindergarten has been (Stetsenko, 2005). This history may reflect clear intentions. However, conscious choices about time regulation may over time become routinised, immanent and taken for granted, so that the justification for regulating time may amount to little more than pointing to having regulated it that way previously.

\subsection{Studying Children's Outdoor Play Activities in Kindergarten}

The fieldwork for this study was conducted in March 2017 with 7 days of observations in a Chinese kindergarten and five ${ }^{2}$ days in a Norwegian kindergarten. The observations were participant observations which consisted of obtaining photos and video of children's activities and play in the outdoor playtime activity setting in each kindergarten. We also obtained insight into the time regulation through observations and interviews of the teachers.

\subsubsection{The Sample of Kindergartens}

The two kindergartens in this study both emphasize children's access to outdoor activities. The Chinese kindergarten is a public kindergarten in one of the suburbs of Beijing and has 300 children from the ages of 2-6 years in 9 classes. The kindergarten is providing approximately $2 \mathrm{~h}$ daily outdoor time for children, in accordance to the demands in the new curriculum guidelines. These outdoor activities range from gardening, animal care, physical exercises, child-initiated play, teacher organized games, and outdoor project work. In addition to activities in the outdoor play

\footnotetext{
${ }^{2}$ The children and the teachers in the Norwegian kindergarten were already familiar with the researcher, so the relation had been previously established. The parents and the children themselves had given their consent to be videotaped.
} 
area, the kindergarten organises projects on a farm connected to the kindergarten and environmental projects in the local surroundings.

The Norwegian kindergarten is situated in the outskirts of Bergen and has 90 children in the from the ages of 1-6 years in 6 groups. It is an outdoor kindergarten, which means that the children and the kindergarten teachers spend most of the day outside, approximately $6 \mathrm{~h}$ in the cold and dark season, and around $8 \mathrm{~h}$ during the summer. Three to four times per week, they go on trips to other play spaces, parks, sport areas, or natural settings to play, ski, ice skate, or mountain walk. Lunch and afternoon snacks are served outside, unless it is very cold or raining heavily.

\subsubsection{Participants}

In the Chinese kindergarten, 30 children and their two kindergarten teachers participated. In the Norwegian kindergarten, 12 children and their two kindergarten teachers participated. All children were $4-5$ years old.

\subsubsection{Empirical Material and Analyses}

The photo and video material from the kindergartens consists of $3 \mathrm{~h}$ of video and more than 100 photos from the Chinese kindergarten and the same amount of material from the Norwegian kindergarten. The empirical material also includes interviews with the principals and kindergarten teachers, framework plans, and time schedules.

The analyses takes as its point of departure the different qualitative levels of interpretation suggested by Hedegaard (2008b), beginning with a common sense interpretation to understand what is occurring in the activity setting. Then the situated practice level is analysed to determine the time regulations in the actual kindergarten context, which is followed by a thematic analysis to obtain an overview of the empirical material and understand the patterns in the pedagogical practices.

\subsection{Ethics}

This study is based on a thorough knowledge of young children's learning and development in ECE and insight into the legislation and purpose of the researched institutions. ${ }^{3}$ We respect children's integrity, safety, and well-being as well as the

\footnotetext{
${ }^{3}$ As researchers, we are situated in the Nordic context, Denmark and Norway, with a solid foundation in ECE, as kindergarten teachers and as kindergarten teacher educators. Additionally, Birkeland has more than 15 years of experience with ECE in China (Birkeland, 2019, 2020), and
} 
children's and kindergarten teachers' right to be anonymous in our research. We were ready to leave the role of researcher and take on the role of responsible adult in every situation during our research (Sørensen, 2014). The Norwegian Centre for Research Data, NSD, has approved the study ethically and the Chinese kindergarten gave permission according to their ethical standards.

\subsection{Findings and Analysis of Empirical Material}

In this section, we will first introduce the general daily time schedule in the two kindergartens. Then we will present the time regulation of different activities during outdoor playtime. Furthermore, we will give examples of the transition between indoor and outdoor activities in the two kindergartens. In the last section, we will present our analysis of how the time regulations give indications of values, expectations/demands, and intentions/goals.

\subsubsection{The General Daily Time Schedule}

Table 7.1 is an overview of the daily time schedule in the two kindergartens. The table illustrates how much time the children spend indoors and outdoors.

Both time schedules include indoor and outdoor activities, meals, and transition periods. The main difference in the two time schedules is the amount of time spent outdoors and indoors. Another significant difference is the period allocated for rest in the Chinese kindergarten.

Table 7.1 Daily activity settings in the two kindergartens

\begin{tabular}{l|l|l}
\hline Time & Activity - China & Activity - Norway \\
\hline $07.00-07.30$ & & Arrival, breakfast and indoor play \\
\hline $07.30-08.00$ & Arrival & \\
\hline $08.00-09.00$ & Corner activity & Transition/bathroom \\
\hline $09.00-09.30$ & Snacks/bathroom & Outdoor playtime \\
\hline $09.30-10.30$ & Activity of the day & \\
\hline $10.30-11.30$ & Outdoor activity & Lunch outdoor \\
\hline $11.30-12.00$ & Lunch & Outdoor playtime \\
\hline $12.00-14.20$ & Sleeping time & \\
\hline $14.20-14.40$ & Snacks & Snacks outdoor \\
\hline $14.40-15.30$ & Outdoor activity & Outdoor playtime \\
\hline $15.30-16.00$ & Indoor activity & \\
\hline $16.00-17.00$ & &
\end{tabular}

Sørensen has several years of experience with outdoor activities in kindergartens in Denmark and Norway (Sørensen, 2013). 
The children in the Chinese kindergarten are expected to be outdoors $2 \mathrm{~h}$ a day according to the Curriculum Guidelines (MOE), see Fig. 7.1. Exceptions to this rule occur during polluted days with bad air quality and days with tough weather conditions, such as heavy rain, snow, or cold weather. Then the children are indoors doing physical training and games. During the 7 days of observation, the children stayed indoors all day one of the days. The schedule has a variety of activities such as corner activity, the activity of the day, outdoor activities, and daily living activities such as meals, hygiene, bathroom visits, and sleeping time. All children leave the kindergarten at the same time at four in the afternoon.

The time schedule in Fig. 7.1 is a visual illustration of children's time spent outdoors and indoors in the Chinese and Norwegian kindergartens. This schedule depicts how much time the children spend outdoors either on trips to other outdoor play spaces or on the playground in the Norwegian kindergarten, totalling $6 \mathrm{~h}$. This is not regulated by the Norwegian curriculum guidelines, named Framework plan, but rather is an institutional choice of being an outdoor kindergarten. The arrival period is not clearly defined with specific activities, but is open to individual choices, breakfast, and play. The transition from indoors to outdoors is based upon individual choices among the children whether they want to go out early or play indoors. There are no organized activities for the children during this period. Additionally, daily living activities such as bathroom visits and hygiene are based upon individual needs. The meals are served outdoors unless it is extremely cold or rainy. The children leave at different times, and they spend approximately 7-8 $\mathrm{h}$ in kindergarten per day. The kindergarten closes at five in the afternoon.

\subsubsection{The Time Schedule on the Outdoor Playground}

When looking specifically at the outdoor activities, one can identify similarities and differences between the two kindergartens.

The total time spent outdoors differs in the two kindergartens, $2 \mathrm{~h}$ and $6 \mathrm{~h}$ for the Chinese and Norwegian kindergartens, respectively (Table 7.2). As a percentage of the time spent outdoors, both kindergartens have time for teacher-organized games, child-initiated activities and transitions. The Chinese kindergarten has additional collective physical training such as Gong Fu and dancing. The Norwegian kindergarten has no such collective physical training; instead the children are physically active when they go walking on trips and when they are playing in nature or at different sport arenas.

The general time schedule for outdoor activities in the Chinese kindergarten does not give a full picture of the clearly structured activities and time regulation. Table 7.3 demonstrates the detailed structure of the outdoor playtime.

The time is clearly structured, as displayed in Table 7.3, providing a specific time schedule for the different activities such as collective physical training, teacher organized games and child-initiated play during this one-hour outdoor playtime. 


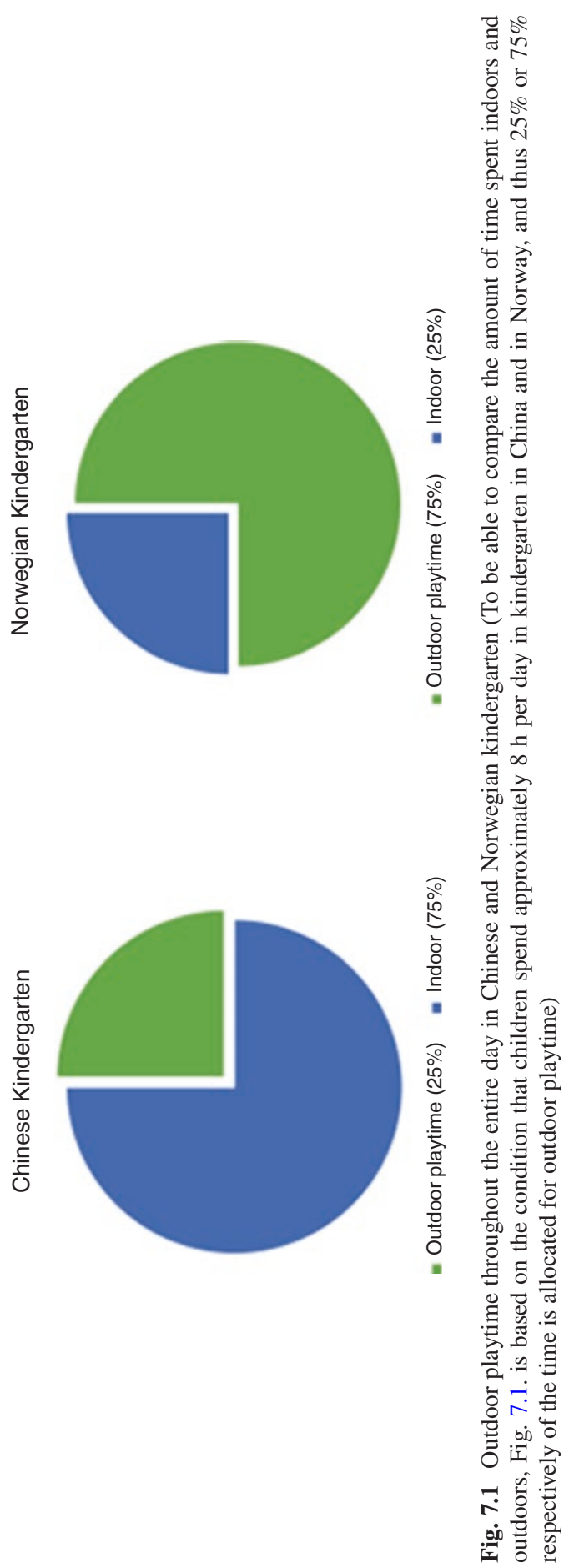


Table 7.2 Amount of time allocated for different activities, as a percentage and minutes of daily outdoor playtime

\begin{tabular}{l|l|l|l|l}
\hline $\begin{array}{l}\text { Activities in the } \\
\text { outdoor time }\end{array}$ & \multicolumn{2}{|l|}{$\begin{array}{l}\text { Chinese kindergarten, amount of } \\
\text { time in different activities outdoor }\end{array}$} & $\begin{array}{l}\text { Norwegian kindergarten, amount of } \\
\text { time in different activities outdoor }\end{array}$ \\
\hline & Percentage & 12 & $0 \%$ & Minutes \\
\hline $\begin{array}{l}\text { Collective } \\
\text { physical training }\end{array}$ & $10 \%$ & 24 & $15 \%$ & 0 \\
\hline $\begin{array}{l}\text { Teacher-organized } \\
\text { activities }\end{array}$ & $20 \%$ & 60 & $60 \%$ & 54 \\
\hline $\begin{array}{l}\text { Child-initiated } \\
\text { activities }\end{array}$ & $50 \%$ & 24 & $15 \%$ & 216 \\
\hline Transitions & $20 \%$ & 0 & $10 \%$ & 54 \\
\hline Meals & $0 \%$ & 120 & $100 \%$ & 36 \\
\hline Total & $100 \%$ & & & 360 \\
\hline
\end{tabular}

Table 7.3 Regulation of outdoor playtime in the Chinese kindergarten

\begin{tabular}{l|l}
\hline Time & Activity \\
\hline $10.30-10.35$ & $\begin{array}{l}\text { Line up in the hall and walk outside } \\
\text { collectively }\end{array}$ \\
\hline $10.35-10.45$ & Collective activity with physical training \\
\hline $10.45-10.50$ & Collective transition to the game area \\
\hline $10.50-11.05$ & Collective teacher organized game \\
\hline $11.05-11.10$ & $\begin{array}{l}\text { Transition to another area of the } \\
\text { playground }\end{array}$ \\
\hline $11.10-11.30$ & Play activities (sand, climbing, bicycle) \\
\hline $11.30-11.35$ & $\begin{array}{l}\text { Collective transition indoors and lunch } \\
\text { time }\end{array}$ \\
\hline
\end{tabular}

The time schedule is also dominated by being a collective time schedule where all the children do the same kind of activity and have collective transition periods.

In contrast to the Chinese outdoor playtime, the Norwegian outdoor playtime is less structured, and there is more time for spontaneous choices and child-initiated activities (Table 7.4).

\subsubsection{Time Regulation of the Transitions Between Activities}

The time regulation is particularly clear during transition time. This is seen in the transition between indoors and outdoors activities and in-between-activities. Here we present two examples of transitions, one from each kindergarten. 
Table 7.4 Regulation of outdoor playtime in the Norwegian kindergarten

\begin{tabular}{l|l}
\hline Time & Activity \\
\hline $08.30-$ & Transition, visiting bathroom, getting dressed and ready to go outside at an \\
10.00 & individual pace \\
\hline $10.00-$ & Outdoor activities, primarily child-initiated activities \\
12.00 & \\
\hline $12.00-$ & Lunch outdoors unless the rain is very heavy \\
12.30 & \\
\hline $12.30-$ & Outdoor activities, primarily child-initiated activities (85\%) and secondary \\
15.00 & teacher-initiated activities (15\%) \\
\hline $15.00-$ & Afternoon snack (fruit and bread) outdoors, unless the rain is very heavy \\
15.30 & \\
\hline $15.30-$ & Outdoor activities until children picked up by parents \\
17.00 & \\
\hline
\end{tabular}

\subsubsection{Transition from Indoor to Outdoor Activities in the Chinese Kindergarten}

It is Monday morning at 10.30. The music is coming on in the classroom and all the children are tidying up after their collective activity, putting their chairs by the tables (ready furnishing for lunch after outdoor playtime).

Observations:

Some children go to the bathroom and some children go to the hallway and line up. After a few minutes all children are ready to walk outdoors. Two of the boys are having fun together, laughing. All the children walk in two lines with the teacher in front down the stairs to the first floor. The stairway has footprints going down on the right side of the stairs, whereas the footsteps going up is on the left side. The children use most of the space when going out and no one corrects them.

The transition period between different activities in the Chinese kindergarten is collectively organised and characterised by routine and efficiency. Due to societal and institutional demands, the children do not go outside if the weather or level of air pollution do not permit it. This means that the issue of taking warm clothes or rain clothes is not applicable. The children often wear their coats on inside in the wintertime and in the summer time there is little use for rain clothes. The children do not need to wait for each other to get dressed, but go directly outside. In addition, the teacher organises the transition between different activities outdoors and the children walk collectively from one area to another.

\subsubsection{Transition from Indoor to Outdoor Activities in the Norwegian Kindergarten}

It is Monday morning around 8 o'clock, and the group has the kindergarten bus at their disposal, so the activity of the kindergarten teacher is concentrated on getting ready to leave. The teachers have different jobs to do; a lot of packing occurs 
because each child must have his or her own backpack with extra clothes, lunch box, and a bottle of water. The kindergarten teachers also bring their own outdoor gear, a first aid kit, coffee, children's knives, and handicraft items.

Observations:

Four boys are together outside the wardrobe, where they are waiting to leave the kindergarten. They were quickly dressed and ready, wanting to wait outside, and spend time playing 'play-fight' on the waiting area. It is a privilege for the eldest to play outside, without supervision, and this is attractive to the four boys. Play-fight is a sort of experimental activity: it is a test of strength, courage, and endurance, both entertaining and scary at the same time. There are different rules in this activity, not all kinds of fighting are accepted, and the fight must stop when one of the participants says 'I'm not okay'. Suddenly, the play-fight gets loud and sounds like someone is in trouble. The teacher opens the door and asks if everything is fine, and reminds the children of some of the rules in play-fight.

When all children are dressed to go and all bags are packed, it is the end of the play-fight activity for this time. The activity was the boys' way of utilising the small amount of time during transition from the indoor to the outdoor program.

The children in the Chinese kindergarten require little time to be dressed for different weather conditions. Rather, the transition was collective and efficient with little time to wait for each other. There were moments of communication between the children, but few playful episodes.

The children in the Norwegian kindergarten spend a significant amount of time training to be dressed for the cold and wet climate and training to be independent in putting their outdoor clothes on. This means that the children have to wait for everyone to finish before leaving for a trip or waiting for a teacher to walk with them to the playground. This provides room for playful episodes and communication for the children.

\subsubsection{Analyses of Values, Expectations, and Goals during Outdoor Playtime}

A common-sense interpretation of the time schedule reveals that it as an important institutional condition in both kindergartens regulating the day and the specific activity setting, and is a situated practice for children's learning, development, and cultural formation. A thematic interpretation of the findings indicates that temporal settings are value-laden and reifications of intentions and goals and clearly define expectations and demands of the children (see Table 7.5).

Studying the time schedule in the Chinese kindergarten demonstrates societal and cultural values of variation and balance. This is expressed in the balance between daily living activities and learning/play activities, between teacher and child-initiated activities, between rest and activity, and between indoor and outdoor activities. In the Norwegian kindergarten, one can clearly identify the importance of outdoor life as the most valuable space for learning and development and the importance of conquering natural elements. 
Table 7.5 Values, expectations, and goals in the time regulation of outdoor playtime

\begin{tabular}{|c|c|c|}
\hline Time regulation & Chinese kindergarten & Norwegian kindergarten \\
\hline \multirow{3}{*}{$\begin{array}{l}\text { Societal and } \\
\text { cultural values }\end{array}$} & Balance as an overall value & Outdoor life as real life \\
\hline & $\begin{array}{l}\text { Children need protection against natural } \\
\text { elements }\end{array}$ & $\begin{array}{l}\text { Children need to experience } \\
\text { natural elements and weather } \\
\text { conditions to become strong }\end{array}$ \\
\hline & $\begin{array}{l}\text { Self-regulation through the collective } \\
\text { group - interdependence }\end{array}$ & $\begin{array}{l}\text { Self-management/autonomy and } \\
\text { independence }\end{array}$ \\
\hline \multirow[t]{4}{*}{$\begin{array}{l}\text { Institutional } \\
\text { goals }\end{array}$} & Efficiency & $\begin{array}{l}\text { Learning and development takes } \\
\text { time }\end{array}$ \\
\hline & Highly structured & Spontaneous structure \\
\hline & $\begin{array}{l}\text { Balance between different activity settings, } \\
\text { between teacher-initiated and children- } \\
\text { initiated activities, rest and activity }\end{array}$ & $\begin{array}{l}\text { Play as the most important } \\
\text { activity to develop }\end{array}$ \\
\hline & Physical training through exercises & $\begin{array}{l}\text { Physical training through play } \\
\text { activities }\end{array}$ \\
\hline \multirow[t]{3}{*}{$\begin{array}{l}\text { Expectations } \\
\text { and demands }\end{array}$} & $\begin{array}{l}\text { Protect themselves from tough weather } \\
\text { conditions }\end{array}$ & Endure tough weather conditions \\
\hline & $\begin{array}{l}\text { Self-regulation by adjusting to the time } \\
\text { schedule of the group }\end{array}$ & $\begin{array}{l}\text { Individual self-regulation - find } \\
\text { meaningful activities within } \\
\text { broad frames for activity }\end{array}$ \\
\hline & Listening to and following instructions & $\begin{array}{l}\text { Take initiative, being } \\
\text { imaginative, creative, and robust }\end{array}$ \\
\hline
\end{tabular}

Furthermore, we found highly specific demands and expectations of the children in both kindergartens. The children in the Chinese kindergarten are supposed to move from inside to outside in an efficient way. Slowing down this transition was regarded as a loss of time. They have limited time on the outdoor playground since the space is shared by many classes at different times, and time should be used efficiently. The transitions between the different activity settings on the outdoor playground are also collective, based upon interdependence and a high degree of efficiency. The time regulation in the Norwegian kindergarten is more individualised and seems to demand more autonomous behaviour. Nevertheless, the Norwegian kindergarten children are expected to be outdoors in any kind of weather. There is also a clear expectation for the children to find meaningful activities in playing outdoors, whether they are on the kindergarten playground or on trips in nature.

\subsection{Discussion}

These findings illustrate that time regulation is not just an organisational issue, but is also influenced by societal values and institutional expectations and demands on what to emphasise in everyday life in kindergarten. In this way, time regulation is an important condition for institutional practices and children's play and cultural formation. 


\subsubsection{Time Regulation as Condition for Institutional Practices}

Many aspects of Chinese early childhood education practices have changed over the past 30 years in accordance with a series of state-led, top-down ECE reforms promoting play-based, child-initiated, and individual-oriented practices (Tobin, Hsueh, \& Karasawa, 2009; Liu \& Tobin, 2018). Contemporary Chinese ECE is a hybrid terrain of old and new practices, producing tensions between Chinese traditional cultural expectations and Western educational values (Liu \& Tobin, 2018).

Traces of this hybrid terrain of contemporary Chinese ECE can be identified in the regulation of time in outdoor playtime. In the 1950s, Chinese early childhood education was highly influenced by ECE in the Soviet Union (Liu \& Tobin, 2018). Activities in kindergarten programs were highly structured with limited time for every lesson, approximately $20 \mathrm{~min}$, with a primary focus on teacher-initiated collective activities (Pan, Wang, \& Li, 2018). This has been the dominant practice in Chinese kindergarten until the last decade. However, the time regulation of outdoor activities is, as reflected in our findings, now highly influenced by the Chinese framework for kindergartens, namely the Early Learning and Development Guidelines for children aged 3-6, which emphasises time for child-initiated play and individual-oriented pedagogy. Outdoor playtime may now be considered a hybrid of collective activities such as guangbo ticao, teacher organized collective games, and child-initiated play activities. This balance of a variety of activity settings in outdoor practice is a predominant feature of the time regulation in this Chinese kindergarten.

Outdoor activities and play have been and are still highly valued in the Norwegian society in general and in early childhood education in particular. Historically, Norwegian kindergartens have emphasised the importance of outdoor play. Moser and Martinsen (2010) found that the general time spent outdoors in summer time was $70 \%$ or two-thirds and in winter time $30 \%$, or one third, of the time. The dominant institutional practice in this particular Norwegian kindergarten is to have outdoor playtime and outdoor activities most of the day. However, in response to discussions of increasing pressure for learning outcomes in Norwegian kindergartens combined with more strict safety rules on the outdoor playground, there is a countermovement emphasising more outdoor activities by establishing outdoor kindergartens. The time regulation in this particular kindergarten is an example of this countermovement, which argues for being outdoors in all weather conditions.

As a consequence of the loose structure of the time regulation, the content of the outdoor playtime is based upon spontaneous decisions and choices and is, as such, less predictable for the children. Most of the activities are based upon children's own initiatives, although teachers decide the time frames of when to undertake specific activities, such as when to go for ice skating or play in the forest. The children can act within a certain frame of possibilities decided by the teachers, and therefore everything is not based on the children's own ideas. This form of time regulation demonstrates that the teachers need to pay attention to both societal and institutional values and plans and adjust this to their knowledge about the particular child. 


\subsubsection{Conditions for Play and Cultural Formation}

A grand narrative of the history of Chinese early childhood education is considered by many researchers as being defined by the hybrid influence of Confucianism, Communism, and Western ideals (Liu \& Tobin, 2018). However, as Liu and Tobin argue, this grand narrative may be reductionist and tautological (2018). All early childhood education is informed, influenced, and inspired by cultural loans. This grand narrative underestimates the complexity and fluidity of Chinese culture and society. Chinese children are introduced to traditional collective physical training, which may seem to contradict the emphasis in the curriculum guidelines on childinitiatives and child-initiated play. Keeping both collective physical training and child-initiated play as activities in outdoor playtime underscores the importance of balance in Chinese early childhood education. The outdoor activities are thus intended to support Chinese traditions and values.

At first glance, the collective movements from indoor to outdoor may be interpreted as exclusively disciplining children's bodies through accommodation to the temporal order, which requires the correct use of time and the children's correct use of their body. This interpretation may overlook the implicit cultural logic about the pleasure of the collective spirit (Liu \& Tobin, 2018). The pleasure of the collective spirit and cultural formation through the group is clearly exemplified by the guangbo ticao, which is only possible to do collectively and which has other dimensions than pure physical training (Liu \& Tobin, 2018).

Simultaneous to cultural formation through collective experiences, the time regulation of the outdoor period in the Chinese kindergarten clearly manifests the importance of individual time. Although the time frame is decided by the teachers with little influence from the children, the children had time for developing their play without corrections or instructions from the teachers. Introducing childinitiated play in accordance with the curriculum guidelines has been a somewhat painful process in Chinese kindergartens (Pan et al., 2018). Child-initiated play has been interpreted in many ways and the teachers have had problems loosening the control and structure. In this kindergarten, it was clearly observed that the time regulation provides conditions for child-initiated play.

Just like the time regulation in China, the time regulation in the Norwegian kindergarten has embedded specific expectations and demands on the children. The children are expected to take the initiative to play and find meaningful activities in nature. This is an example of giving children 'action space' in the educational environment (Nordin-Hultman, 2004). Other expectations and demands are to be selforganised, organising the play, and individually deciding on playmates. These expectations do not express an emerging practice. Quite the contrary, these expectations have been dominant practice for a long time in Norway. The notion of free play, meaning that children are supposed to take the initiative and decide the topic of play, play-materials, and who to play with have been dominant practice in Norwegian kindergartens for decades and even more so during outdoor play 
(Kallestad \& Ødegaard, 2013). In this way, one can say that the children demonstrate self-regulation by organising their own activities.

\subsection{Concluding Remarks}

As illustrated in this chapter, the question of time regulation in kindergartens is not simply an organisational, structural question of division of labor and shared playground. Implicit cultural beliefs with different values, expectations, and demands are embedded in the regulation of time in both kindergartens. In turn, these time regulations in kindergartens establish the conditions for different institutional practices as well as conditions for children's play and cultural formation.

The implicit cultural logic in the Chinese kindergarten indicates the importance of collective spirit of living in harmony with others. The time regulation has a repetitive character of bodily practices combining self-discipline, perfection through rigorous training, and social harmony. The time regulation in the Chinese kindergarten further illustrates the importance of balance: balance between teacher-initiated activities and child initiated activities, balance between physical training and play, balance between large group activities and individual/small group activities, and balance between activity and rest. The transition periods demand efficiency and give little space for children's spontaneous playful episodes and communication.

The implicit cultural logic in the Norwegian kindergarten implies the importance of enduring and conquering nature and weather conditions. The children are supposed to find meaningful activities and be self-organised. The loosely structured transition periods can result in much waiting time; therefore, practitioners expect the children to make these periods meaningful for themselves. The expectations of taking the initiative and being autonomous are prevalent.

Due to the changing demands from curriculum guidelines and education frameworks, the question of time regulation needs to be addressed. Changes in curriculum guidelines with an emphasis on play and outdoor must be followed up by questions of time regulations and changes in these guidelines. As illustrated in the Chinese kindergarten, the kindergarten has made changes in the amount of outdoor time and the amount of time allocated for child-initiated play after the curriculum reforms. The findings and discussion in this article highlights the importance of conducting qualitative in-depth studies of how the regulation of time impacts pedagogical practices in kindergartens and our understanding of children's cultural formation.

Acknowledgements We acknowledge support from The Research Council of Norway (project code 275575), Kindergarten Knowledge Centre for Systemic Research on Diversity and Sustainable Futures (KINDknow), Western Norway University of Applied Sciences Norwegian Agency for International Cooperation and Quality Enhancement in Higher Education (Diku) and VIA University College, Denmark. 


\section{References}

Bang, J. (2009). An environmental affordance perspective on the study of development - Artefacts, social others, and self. In M. Fleer, M. Hedegaard, \& J. Tudge (Eds.), Childhood studies and the impact of globalization: Policies and practices at global and local levels. New York: Routledge.

Birkeland, A. (2019). Temporal settings in kindergarten: A lens to trace historical and current cultural formation ideals? Journal of European Early Childhood Education and Care Research, 27(1), 53-67.

Birkeland, Å. (2020). Contradictory cultural formation ideals in a time of increased emphasis on individualization. A cross-cultural study of kindergarten practices in China and Norway. Doctoral Thesis NTNU:344.

Brussoni, M., Gibbons, R., \& Gray, C. (2015). What is the relationship between risky outdoor play and health in children? A systematic review. International Journal of Environmental Research and Public Health, 12(6), 6423-6454.

Dowda, M., Pate, R. R., Trost, S. G., Almeida, M. J., \& Sirard, J. R. (2004). Influences of preschool policies and practices on children's physical activity. Journal of Community Health, 29(3), 183-196.

Dowda, M., Pfeiffer, K. A., Brown, W. H., Mitchell, J. A., Byun, W. And Pate, R. R. (2011). Parental and environmental correlates of physical activity of children attending preschool. Journal of Archives, Pediatrics and Adolescent Medicine 165 (10), 939-944.

Flyvbjerg, B. (2011). Case study. In N. Denzin \& Y. Lincoln (Eds.), The sage handbook of qualitative research (4th ed.). Los Angeles: Sage.

Framework Plan for Kindergartens. Norwegian Directorate for Education and Training (2017).

Gulløv, E., \& Højlund, S. (2003). Feltarbejde blandt børn. Metodologi og etik i etnografisk børneforskning. København, Denmark: Gyldendal.

Hammer, A. S. E., \& He, M. (2016). Preschool teachers' approaches to science: A comparison of a Chinese and a Norwegian kindergarten. European Early Childhood Education Research Journal, 24(3), 450-464.

Hedegaard, M. (2008a). A cultural-historical theory of children's development. In M. Hedegaard $\&$ M. Fleer with J. Bang and P. Hviid (Eds.), Studying children: A cultural-historical approach. Maidenhead, UK: Open University Press.

Hedegaard, M. (2008b). Developing a dialectic approach to reearching children's development. In M. Hedegaard \& M. Fleer with J. Bang and P. Hviid (Eds.), Studying children: A culturalhistorical approach. Maidenhead, UK: Open University Press.

Hedegaard, M. (2009). Children's development from a cultural-historical approach: Children's activity in everyday local settings as foundation for their development. Mind, Culture and Activity, 16(1), 64-81.

Hedegaard, M. (2012). Analyzing Children's learning and development in everyday settings from a cultural-historical wholeness approach. Mind, Culture, and Activity, 19(2), 127-138.

Hedegaard, M. (2014). The significance of demands and motives across practices in children's learning and development: An analysis of learning in home and school. Learning, Culture and Social Interaction, 3(3), 188-194.

Hu, B. Y., Marco, A. D., \& Chen, Y. (2015). Examining the quality of outdoor play in Chinese kindergartens. International Journal of Early Childhood, 47(1), 53-77.

Kallestad, J. H., \& Ødegaard, E. E. (2013). Children's activities in Norwegian kindergartens. Part 1: An overall picture. Cultural Historical Psychology, 10(2), 86-94.

Karlsson, M. (2012). Fysisk aktivitet öker benmassan hos barn men endast obetydligt hos vuxna. Malmø,Sweden: Ortopediska kliniken, Universitetssjukhuset MAS.

Leontiev, A. N. (2005). Study of the environment in pedological works of L.S. Vygotsky. A critical study. Journal of Russian and East European Psychology, 43(4), 8-28.

Liu, C., \& Tobin, J. (2018). Group exercise in Chinese preschools in an era of child-centered pedagogy. Comparative Education Review, 62(1), 5-30. 
Moser, T., \& Martinsen, M. T. (2010). The outdoor environment in Norwegian kindergartens as pedagogical space for todllers' play, learning and development. European Early Childhood Education Research Journal, 18(4), 457-471.

Nordin-Hultman, E. (2004). Pedagogiska miljøer och subjektskapande. Stockholm: Liber.

Pan, Y., Wang, X., \& Li, L. (2018). Early childhood education and development in China. In M. Fleer \& B. V. Oers (Eds.), International handbook of early childhood education. Dorthrecht, The Netherlands: Springer.

Sandseter, E. B., \& Lysklett, O. B. (2017). Outdoor education in the Nordic region. In C. Ringsmose \& G. Kragh-Muller (Eds.), Nordic Social Pedagogic Approaches to Early Years. E-book. Cham, Switzerland: Springer.

Sommer, D. (2003). Barndomspsykologi. Udvikling i en forandret verden. Copenhagen, Denmark: Kbh: Hans Reitzels Forlag.

Sørensen, H. V. (2013). Børns fysiske aktivitet i børnehaven: en analyse af 5-6 årige børns muligheder og betingelser for fysisk aktivitet. Aarhus, Denmark: Viasystime.

Sørensen, H. V. (2014). Ethics in researching young children's play in preschool. In M. Fleer \& A. Ridgway (Eds.), Visual methodologies and digital tools for researching with young children. Dorthrecht, The Netherlands: Springer.

Sørensen, H. V., \& Birkeland, A. (2020). Children's explorative activities in kindergarten playgrounds: A case study in China and Norway. In M. Hedegaard \& E. E. Ødegaard (Eds.), Children's exploration and cultural formation. Cham, Switzerland: Springer.

Stake, R. E. (2005). Qualitative case studies. In N. Denzin \& Y. Lincoln (Eds.), The Sage handbook of qualitative research (pp. 443-466). Thousand Oaks, CA: Sage.

Statistic Norway. (2019). Barnehagedekning, før og nå. www.ssb.no

Stetsenko, A. (2005). Activity as object-related: Resolving the dichotomy of individual and collective planes of activity. Mind, Culture, and Activity, 12(1), 70-88.

Tobin, J. J., Hsueh, Y., \& Karasawa, M. (2009). Preschool in three cultures revisited: China, Japan and the United States. Chicago: University of Chicago Press.

Vygotsky, L. (1998). Child psychology. The collected work of L. S. Vygotsky: Vol. 5. New York: Plenum Press.

Vygotsky, L. S. (2016/1966). Play and its role in the mental development of the child. International Research in Early Childhood Education, 7 (2), 1-23.

Waller, T., Ærleman-Hagser, E., \& Sandseter, E. B. (2017). The sage handbook of outdoor play and learning. Los Angeles: Sage.

Wang, X., Woolley, H., Tang, Y., Liu, H., \& Luo, Y. (2018). Young children's and adults' perceptions of natural play spaces: A case study from Chengdu. Cities, 7, 173-180.

Yin, R. K. (2009). Case study research: Design and methods. Los Angeles: Sage.

Open Access This chapter is licensed under the terms of the Creative Commons Attribution 4.0 International License (http://creativecommons.org/licenses/by/4.0/), which permits use, sharing, adaptation, distribution and reproduction in any medium or format, as long as you give appropriate credit to the original author(s) and the source, provide a link to the Creative Commons license and indicate if changes were made.

The images or other third party material in this chapter are included in the chapter's Creative Commons license, unless indicated otherwise in a credit line to the material. If material is not included in the chapter's Creative Commons license and your intended use is not permitted by statutory regulation or exceeds the permitted use, you will need to obtain permission directly from the copyright holder.

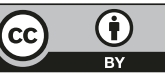

